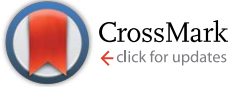

Cite this: Chem. Sci., 2015, 6, 3420 Accepted 14th April 2015

DOI: $10.1039 / c 5 s c 00618 j$

www.rsc.org/chemicalscience
Received 17th February 2015

\section{Hydration of guanidinium depends on its local environment $\uparrow$}

\author{
Sven Heiles, Richard J. Cooper, Matthew J. DiTucci and Evan R. Williams*
}

Hydration of gaseous guanidinium $\left(\mathrm{Gdm}^{+}\right)$with up to 100 water molecules attached was investigated using infrared photodissociation spectroscopy in the hydrogen stretch region between 2900 and $3800 \mathrm{~cm}^{-1}$. Comparisons to IR spectra of low-energy computed structures indicate that at small cluster size, water interacts strongly with $\mathrm{Gdm}^{+}$with three inner shell water molecules each accepting two hydrogen bonds from adjacent $\mathrm{NH}_{2}$ groups in $\mathrm{Gdm}^{+}$. Comparisons to results for tetramethylammonium $\left(\mathrm{TMA}^{+}\right.$) and $\mathrm{Na}^{+}$ enable structural information for larger clusters to be obtained. The similarity in the bonded $\mathrm{OH}$ region for $\mathrm{Gdm}\left(\mathrm{H}_{2} \mathrm{O}\right)_{20}{ }^{+}$vs. $\mathrm{Gdm}\left(\mathrm{H}_{2} \mathrm{O}\right)_{100}{ }^{+}$and the similarity in the bonded $\mathrm{OH}$ regions between $\mathrm{Gdm}^{+}$and $\mathrm{TMA}^{+}$but not $\mathrm{Na}^{+}$for clusters with $<50$ water molecules indicate that $\mathrm{Gdm}^{+}$does not significantly affect the hydrogen-bonding network of water molecules at large size. These results indicate that the hydration around $\mathrm{Gdm}^{+}$changes for clusters with more than about eight water molecules to one in which inner shell water molecules only accept a single $\mathrm{H}$-bond from $\mathrm{Gdm}^{+}$. More effective $\mathrm{H}$-bonding drives this change in inner-shell water molecule binding to other water molecules. These results show that hydration of $\mathrm{Gdm}^{+}$depends on its local environment, and that $\mathrm{Gdm}^{+}$will interact with water even more strongly in an environment where water is partially excluded, such as the surface of a protein. This enhanced hydration in a limited solvation environment may provide new insights into the effectiveness of $\mathrm{Gdm}^{+}$as a protein denaturant.

\section{Introduction}

Ions are ubiquitous in solution where they play important roles in many different processes in chemistry and biology. ${ }^{1-7}$ Interface phenomena of ions in water, such as the surface activity of ions, ${ }^{1-3}$ or ions in electrochemical processes, ${ }^{5,6}$ have been investigated with a variety of both experimental and computational methods. Arguably, one of the most widely investigated, yet, still hotly debated areas of ion phenomena is the role various salts have on the stabilities of native protein structures. ${ }^{7,8}$ Results from many studies have led to the phenomenological ordering of both anionic and cationic ions based on their effect at either stabilizing or destabilizing the folded structures of proteins, referred to as the "Hofmeister series", named after the person who first established this ordering over

Department of Chemistry, University of California, B42 Hildebrand Hall, Berkeley, CA 94720,USA.E-mail: erw@berkeley.edu

$\dagger$ Electronic supplementary information (ESI) available: Full citation for ref. 51, experimental details and reproducibility of the IRPD measurements, comparison between experimental IRPD spectra with harmonic IR spectra of energetic low lying isomers for $\left[\mathrm{Gdm}\left(\mathrm{H}_{2} \mathrm{O}\right)_{n}\right]^{+}, n=6-9$, structures of the energetic low lying isomers of $\left[\mathrm{Gdm}\left(\mathrm{H}_{2} \mathrm{O}\right)_{n}\right]^{+}, n=6-9$, and representative structures of $\left[\mathrm{Gdm}\left(\mathrm{H}_{2} \mathrm{O}\right)_{n}\right]^{+},\left[\mathrm{Na}\left(\mathrm{H}_{2} \mathrm{O}\right)_{n}\right]^{+},\left[\mathrm{TMA}\left(\mathrm{H}_{2} \mathrm{O}\right)_{n}\right]^{+}$, with $n=20$ and 40 . Quantitative comparison of the spectra for $\mathrm{Gdm}^{+}, \mathrm{Na}^{+}$and $\mathrm{TMA}^{+}$with $n=$ 20-100 in the HB stretching region. See DOI: 10.1039/c5sc00618j

+ Current address: Institute of Inorganic and Analytical Chemistry, Justus-Liebig-University Giessen, 35392 Giessen, Germany. a century ago. ${ }^{7-9}$ A similar ordering of ions occurs for salt solubilities ${ }^{\mathbf{1 0 , 1 1}}$ and cloud points of nonionic surfactants. ${ }^{\mathbf{1 2}}$ The effects of ions on protein stability have been attributed to direct ion-protein interactions $\mathrm{s}^{\mathbf{8 , 1 3 - 1 7}}$ and to ion-water interactions $\mathrm{s}^{\mathbf{1 8 - 2 0}}$ that might affect the hydrogen-bonding network of water molecules that surround proteins.

Of the ions in the Hofmeister series, none is more widely investigated or arguably more important to understand than guanidinium $\left(\mathrm{Gdm}^{+}\right) \cdot{ }^{21-24} \mathrm{Gdm}^{+}$is widely used to destabilize or denature proteins in the form of $\mathrm{GdmCl}$ or $\mathrm{GdmSCN},{ }^{\mathbf{1 4 , 1 5 , 2 2}}$ and is often used to rationalize the physical origins of the Hofmeister series. ${ }^{7,8}$ Yet, this ion does not follow the general ordering in charge density observed in the cationic series, ${ }^{\mathbf{1 1}}$ where low charge density ions, such as tetramethylammoni$\mathrm{um},{ }^{25}$ stabilize native protein structure, whereas high density ions, such as $\mathrm{Mg}^{2+}$ (ref. 10) or $\mathrm{Al}^{3+}$ (ref. 26) are destabilizing.

Molecular dynamics (MD) simulations have been used to study various types of ion-protein interactions which could be responsible for the propensity of $\mathrm{Gdm}^{+}$to disrupt the native structure of proteins. ${ }^{16,27-37}$ Various types of $\mathrm{Gdm}^{+}$interactions to proteins have been identified by these studies: the interaction to polar or charged side chain groups, ${ }^{27-30}$ hydrogen bonding to amino acid side chain groups or the peptide backbone ${ }^{29-32}$ and interactions with weakly hydrated, non-polar residues of the protein, i.e., "hydrophobic" interactions to aliphatic ${ }^{33,37}$ or aromatic groups. ${ }^{16,28,31-33,36}$ 
Although many sites of interaction between $\mathrm{Gdm}^{+}$and various regions of proteins have been identified, there is only limited direct experimental evidence for these types of interactions ${ }^{13-17,22,23,38-40}$ Results from calorimetric measurements indicate a higher local concentration of $\mathrm{Gdm}^{+}$ions at protein surfaces compared to neutral urea molecules, leading the authors to conclude that this difference is due to interactions of $\mathrm{Gdm}^{+}$with negatively charged protein side chains. ${ }^{17}$ Results from base catalysed hydrogen exchange indicate that $\mathrm{Gdm}^{+}$ does not interact with the peptide backbone. ${ }^{38}$ Saykally and coworkers recently found evidence for $\mathrm{Gdm}^{+}-\mathrm{Gdm}^{+}$pairs from Xray absorption spectroscopy suggesting favourable dispersion interactions between the ions, which could be important to understanding interactions between $\mathrm{Gdm}^{+}$and arginine. ${ }^{41}$ This like-ion pair formation is consistent with some MD simulations. ${ }^{34}$ Results from small angle neutron scattering indicate a preferential interaction of $\mathrm{Gdm}^{+}$with aromatic compared to aliphatic groups. ${ }^{16}$ Wouterson and co-workers found that $\mathrm{Gdm}^{+}$ preferentially destabilized $\beta$-sheets over $\alpha$-helices in model proteins which they related to the specific disruption of "hydrophobic" interactions by $\mathrm{Gdm}^{+}{ }^{40}$ This interpretation is consistent with the idea that "hydrophobic" interactions promote the formation of $\beta$-sheets, whereas they are only of minor importance for the stabilities of $\alpha$-helices. ${ }^{42}$ Despite the many methods used to study the mechanism of protein structure destabilization by $\mathrm{Gdm}^{+}$, the relative contributions of the many different possible interactions of $\mathrm{Gdm}^{+}$with proteins as well as the role of $\mathrm{Gdm}^{+}$-water interactions remain a hotly debated topic.

Interactions between $\mathrm{Gdm}^{+}$and water have been investigated, ${ }^{18,36,43-49}$ and some information about how water organizes around $\mathrm{Gdm}^{+}$forming a first solvation shell comes from neutron diffraction studies. ${ }^{36,45}$ The diffraction amplitude from water molecules that are in contact with $\mathrm{Gdm}^{+}$is weak compared to that of many other ions, leading Mason et al. to conclude that $\mathrm{Gdm}^{+}$is weakly hydrated..$^{36,45} \mathrm{MD}$ simulations show that the neutron scattering data is consistent with linear $\mathrm{NH}^{\cdots} \mathrm{OH}_{2} \mathrm{H}$-bonds between water molecules in the first hydration shell and $\mathrm{Gdm}^{+} .{ }^{36}$ These simulations also indicate that the density of water molecules above and below the molecular plane of $\mathrm{Gdm}^{+}$is much lower than that of bulk water indicating that these planes of the ion are "hydrophobic" ${ }^{36}$ Results from dielectric relaxation spectroscopy indicate that $\mathrm{Gdm}^{+}$salts have a minimal effect on the relaxation time constant of aqueous $\mathrm{GdmCl}$ solutions up to $\sim 7 \mathrm{M}$ when compared to that of pure water, consistent with the concept of weak $\mathrm{Gdm}^{+}$hydration. ${ }^{44}$ Similar conclusions have been drawn from conductivity ${ }^{46}$ and femtosecond $\mathrm{IR}^{47}$ measurements. However, a more detailed molecular level understanding of how water interacts with $\mathrm{Gdm}^{+}$remains elusive.

Here, the hydration of $\mathrm{Gdm}^{+}$is investigated by measuring infrared photodissociation (IRPD) spectra of mass selected gaseous clusters that are temperature controlled and trapped in the ion cell of a Fourier-transform ion cyclotron resonance (FTICR) mass spectrometer. For clusters with fewer than 10 water molecules, detailed information about $\mathrm{Gdm}^{+}$-water interactions are obtained from comparisons to IRPD spectra of computed low-energy structures. For clusters with up to 100 water molecules, comparisons are made to spectra of reference ions that interact weakly or more strongly with water. These results show that hydration of $\mathrm{Gdm}^{+}$is different at small $v s$. large cluster size. $\mathrm{Gdm}^{+}$is weakly hydrated at large cluster size, consistent with previously published reports, but this ion is more strongly hydrated at small cluster size where the arrangement of water molecules differs from that in bulk. These results indicate that the interactions of $\mathrm{Gdm}^{+}$with water depend on its local environment, and these results may shed new light into the effectiveness of $\mathrm{Gdm}^{+}$as a protein denaturant.

\section{Methods}

\section{Mass spectrometry and IRPD spectroscopy}

All experiments were performed using a 7.0 T FT-ICR mass spectrometer, which is based on a $2.75 \mathrm{~T}$ FT-ICR instrument that is described elsewhere. ${ }^{50}$ Briefly, hydrated ions are generated by nanoelectrospray ionization (nESI) from 3-5 mM solutions of guanidinium $\left(\mathrm{Gdm}^{+}\right)$, tetramethylammonium $\left(\mathrm{TMA}^{+}\right)$, sodium and cesium chloride salts dissolved in purified water (milli-Q-purification, Millipore, MA, U.S.A.). These solutions are loaded into borosilicate capillaries that have tips that are pulled to an inner diameter of $\sim 1 \mu \mathrm{m}$. A voltage of $+650-800 \mathrm{~V}$ relative to the heated metal entrance capillary of the mass spectrometer is applied to a platinum filament that is in contact with the sample solution to produce ion-containing nanodrops. The hydrated ions are introduced into the mass spectrometer and are guided into the FT-ICR cell through five stages of differential pumping using electrostatic lenses. A pulse of dry nitrogen gas ( $\sim 10^{-6}$ Torr) is introduced into the vacuum chamber during ion accumulation $(\sim 5 \mathrm{~s})$ to enhance trapping and thermalisation of the ions to the temperature of the surrounding copper jacket. The copper jacket is temperature regulated at $133 \mathrm{~K}$ using a controlled flow of liquid nitrogen. After ion accumulation, the pressure returns to $<10^{-8}$ Torr after $\sim 5 \mathrm{~s}$. Ions of interest are subsequently mass selected by applying a stored waveform inverse Fourier transform waveform. For ions with fewer than 75 water molecules attached, a single precursor ion is isolated, whereas for all larger clusters, an ensemble consisting of three consecutive hydration states is mass selected.

Rate constants for blackbody infrared radiative dissociation (BIRD), which occurs as a result of precursor ions absorbing blackbody photons emitted from the surrounding ion cell and copper jacket, are determined from the precursor and product ion abundances for times between 0.5 and $5.0 \mathrm{~s}$. Infrared photodissociation (IRPD) spectra between 2900 and $3800 \mathrm{~cm}^{-1}$ are measured by irradiating the precursor ions with tuneable IR light, which results in increased rates of water molecule loss when the radiation is resonantly absorbed. A spectrum is obtained from the frequency dependent dissociation rate constants corrected for the irradiation time, laser power, and dissociation due to BIRD. Laser light at a repetition rate of $10 \mathrm{~Hz}$ is generated by an OPO/OPA system (LaserVision, Bellevue, WA, U.S.A.) pumped by the fundamental $(1064 \mathrm{~nm})$ of a Nd:YAG laser (Continuum, Surelight I-19, Santa Clara, CA, U.S.A.). The 
ion radiation time is chosen to produce significant, but not complete depletion of the precursor ions (typically 0.5-1.0 s) when absorption occurs. A MIDAS data system is used to record the ion signals and all data handling and analysis is done with in-house routines within Matlab 2013a (The MathWorks, Natick, MA, U.S.A.).

\section{Computational chemistry}

Low-energy structures were identified using conformational searches consisting of 1000 individual steps using Macromodel 9.1 (Schrödinger Inc., Portland, OR, U.S.A.) using the OPLS2005 force field. A single search was done for small clusters, whereas up to five conformational searches starting with different initial structures were done for the larger clusters. Between two and five low-energy structures were reoptimized at the B3LYP/6$31++\mathrm{G}^{* *}$ level of theory, followed by a harmonic frequency analysis. The water binding energy of $\mathrm{H}_{2} \mathrm{O}$ to $\mathrm{Gdm}\left(\mathrm{H}_{2} \mathrm{O}\right)^{+}$was obtained from various low-energy isomeric structures of $\operatorname{Gdm}\left(\mathrm{H}_{2} \mathrm{O}\right)_{2}{ }^{+}$, correcting for the basis set superposition error using the counterpoise method. Q-Chem 4.0 (Q-Chem, Inc., Pittsburgh, PA, U.S.A.) ${ }^{51}$ was used for all quantum chemical computations. Relative Gibbs free energies as a function of temperature were determined from the rotational constants, unscaled harmonic frequencies and electronic ground state energies using an in-house Matlab 2013a (The MathWorks, Natick, MA, U.S.A.) routine.

\section{Results and discussion}

\section{Evolution of IRPD spectra of $\operatorname{Gdm}\left(\mathrm{H}_{2} \mathrm{O}\right)_{n}{ }^{+}$with cluster size}

IRPD spectra of $\mathrm{Gdm}^{+}$with between 5 and 100 water molecules attached in the spectral range between 2900 and $3800 \mathrm{~cm}^{-1}$ were measured at $133 \mathrm{~K}$ (Fig. 1). The spectra can be divided into three partially overlapping regions. The free $\mathrm{OH}(\mathrm{fOH})$ region is between $\sim 3650$ and $3800 \mathrm{~cm}^{-1}$ and corresponds to vibrational motions of unperturbed $\mathrm{OH}$ bonds of water. ${ }^{52-60}$ Vibrations in this region provide information about the local environment and possible long-range effects of the ion on the hydrogen bonding networks of water molecules at the surface of the cluster. $^{20}$ The two spectral regions from $\sim 2900-3650 \mathrm{~cm}^{-1}$ and $\sim 3350-3550 \mathrm{~cm}^{-1}$ correspond to hydrogen bonded $\mathrm{OH}$ and $\mathrm{NH}_{2}$ stretches, respectively. Information about the organization of the hydrogen-bonded ( $\mathrm{HB})$ water molecules in the ion-containing aqueous nanodrops can be obtained from these bands. ${ }^{19,53-60}$

Comparisons between experimental and calculated spectra of low-energy structures can provide detailed information about ion structure(s), and structural conclusions based on such comparisons for $\operatorname{Gdm}\left(\mathrm{H}_{2} \mathrm{O}\right)_{n}{ }^{+}$with $n=1-5$ are reported elsewhere. ${ }^{49}$

These results indicate that there are three water molecules in the inner shell which each bind in the interstitial sites and accept hydrogen bonds from adjacent $\mathrm{NH}_{2}$ groups, and that additional water molecules form a second solvation shell. Extending these detailed comparisons to much larger clusters is challenging owing to the broad spectral features in the
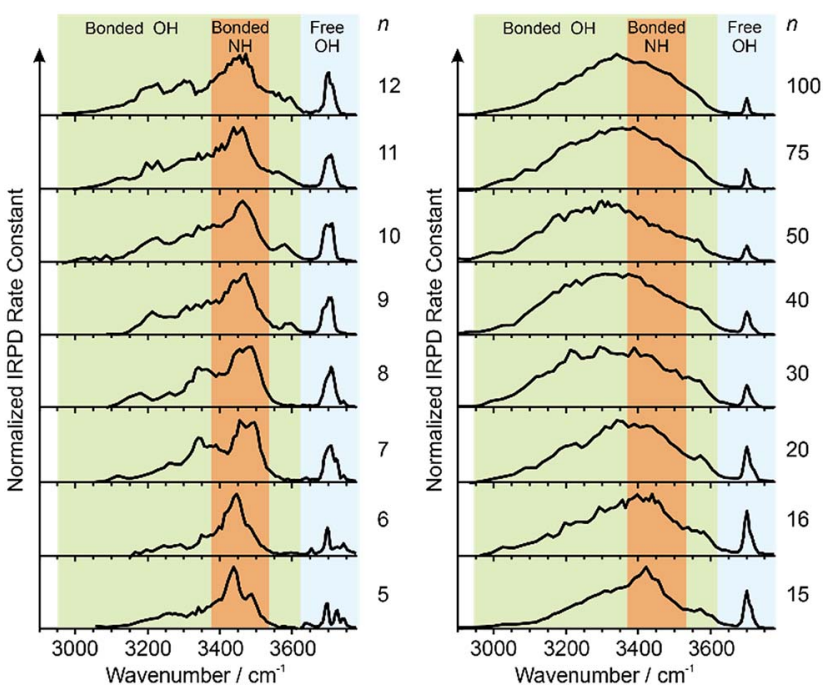

Fig. 1 IRPD spectra measured between $2900-3800 \mathrm{~cm}^{-1}$ at $133 \mathrm{~K}$ for $\left[\mathrm{Gdm}\left(\mathrm{H}_{2} \mathrm{O}\right)_{n}\right]^{+}$. The free $\mathrm{OH}\left(\sim 3650-3800 \mathrm{~cm}^{-1}\right)$, bonded $\mathrm{NH}_{2}$ $\left(\sim 3650-3800 \mathrm{~cm}^{-1}\right)$ and bonded $\mathrm{OH}\left(\sim 3650-3800 \mathrm{~cm}^{-1}\right)$ regions are shaded in blue, orange and green, respectively.

measured spectra and the potentially large number of coexisting and interconverting isomers that are likely present. In order to gain useful information from much larger clusters, comparisons are made to the same size clusters that contain ions for which some structural information is known or can be inferred based on known properties.

\section{Reference ions}

Identifying suitable reference ions for which information about water organization around the ion is known or can be reasonably surmised can be challenging for a number of reasons. The direct interaction between water molecules in the first hydration shell and the ion can influence the arrangement of water molecules in the subsequent hydration shells, ${ }^{\mathbf{1 9 2 0}}$ as can the excluded volume (ion size effect) ${ }^{52}$ or the ion charge state. ${ }^{61}$ Ions that can form strong hydrogen bonds to water molecules, such as $\mathrm{Gdm}^{+}$or $\mathrm{SO}_{4}{ }^{2-}$, can have competing hydration motifs that can potentially further complicate comparisons. Monovalent alkali metal ions are simple, non-reactive ions that do not hydrogen bond to water. ${ }^{62} \mathrm{Cs}^{+}$is the largest nonradioactive ion in this series with an ionic radii of $167 \mathrm{pm},{ }^{63}$ which is less than the ionic radius of $\mathrm{Gdm}^{+}$in the axial $(190 \mathrm{pm})^{21}$ and radial (230 $\mathrm{pm})^{21}$ directions. Normalized IRPD spectra of $\operatorname{Gdm}\left(\mathrm{H}_{2} \mathrm{O}\right)_{20}{ }^{+}$and $\mathrm{Cs}\left(\mathrm{H}_{2} \mathrm{O}\right)_{20}{ }^{+}$are shown in Fig. 2a.

There are two striking features that differentiate the spectra of these clusters. There is only a single band in the $\mathrm{fOH}$ region for $\mathrm{Cs}^{+}$indicating a single type of water molecule with a $\mathrm{fOH}$ stretch at the surface of the cluster, whereas this band is broader in the spectrum of $\mathrm{Gdm}^{+}$, which indicates that there are contributions from a second type of water molecule with a fOH stretch at the cluster surface. The intensity between $\sim 3500$ and $3600 \mathrm{~cm}^{-1}$ for $\mathrm{Cs}^{+}$is greater than that for $\mathrm{Gdm}^{+}$. The band at $\sim 3550 \mathrm{~cm}^{-1}$ and the relatively sharp fOH band in the spectrum of $\mathrm{Cs}^{+}$is due to a water-clathrate cage around the ion. ${ }^{64,65} \mathrm{Such}$ a 

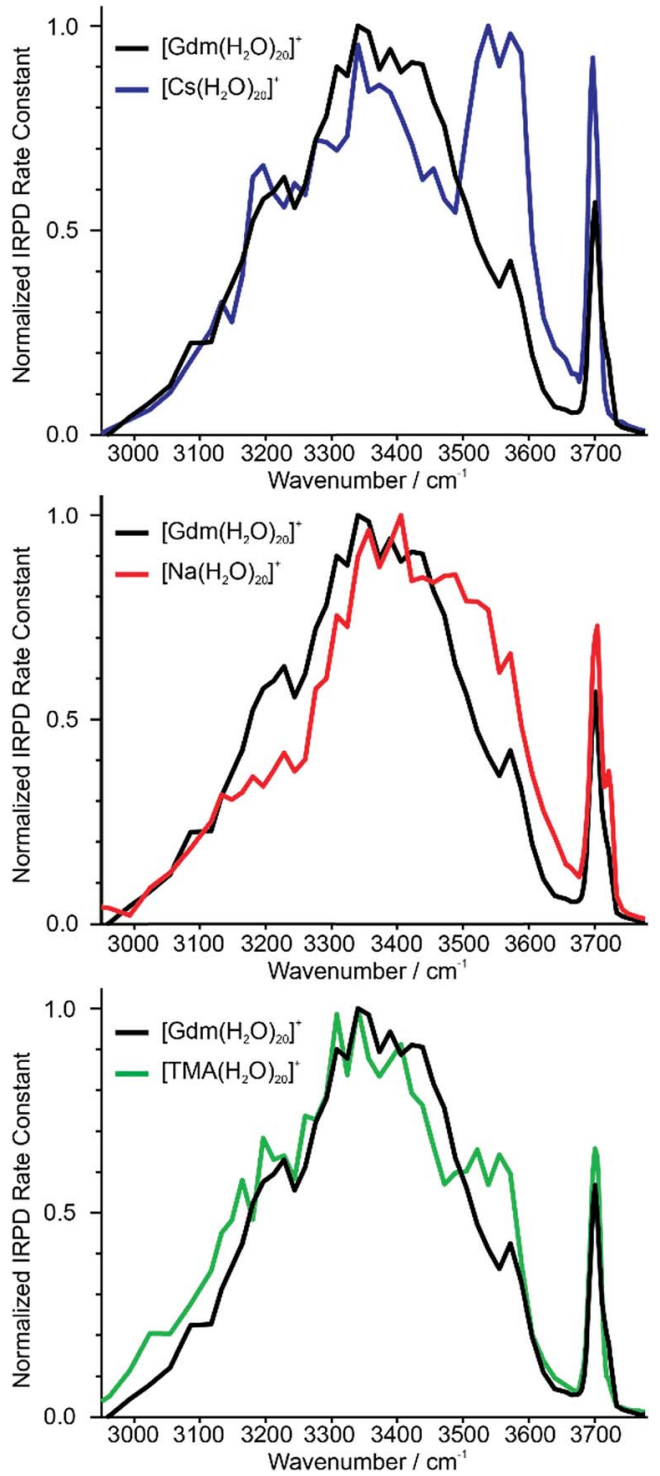

Fig. 2 Comparison of IRPD spectra between 2900-3800 $\mathrm{cm}^{-1}$ measured at $133 \mathrm{~K}$ of $\left[\mathrm{Cs}\left(\mathrm{H}_{2} \mathrm{O}\right)_{20}\right]^{+}$(blue), $\left[\mathrm{Na}\left(\mathrm{H}_{2} \mathrm{O}\right)_{20}\right]^{+}$(red) and $\left[\mathrm{TMA}\left(\mathrm{H}_{2} \mathrm{O}\right)_{20}\right]^{+}$(green) clusters to $\left[\mathrm{Gdm}\left(\mathrm{H}_{2} \mathrm{O}\right)_{20}\right]^{+}$(black)

cage structure also occurs for $\mathrm{K}\left(\mathrm{H}_{2} \mathrm{O}\right)_{20}{ }^{+}$and $\mathrm{Rb}\left(\mathrm{H}_{2} \mathrm{O}\right)_{20}{ }^{+}$. The extent to which the clathrate structure around these ions affects the hydrogen-bonding network of water at larger cluster sizes is not known.

In contrast to these larger ions, $\mathrm{Na}^{+}$does not induce the formation of a surrounding clathrate, ${ }^{64}$ although it interacts strongly with water. Despite its much smaller size, $\mathrm{Na}^{+}(102 \mathrm{pm}$ (ref. 63)) was selected as a reference for an ion that is located centrally in the cluster and does not participate in hydrogen bonding to water molecules. ${ }^{53,64}$ The spectrum of $\mathrm{Na}\left(\mathrm{H}_{2} \mathrm{O}\right)_{20}{ }^{+}$ and $\operatorname{Gdm}\left(\mathrm{H}_{2} \mathrm{O}\right)_{20}{ }^{+}$are compared in Fig. 2b. The spectrum of $\mathrm{Na}\left(\mathrm{H}_{2} \mathrm{O}\right)_{20}{ }^{+}$has two fOH bands but no prominent feature in the bonded $\mathrm{OH}$ region. The broad bonded $\mathrm{OH}$ band is blue shifted compared to that in the spectrum of $\operatorname{Gdm}\left(\mathrm{H}_{2} \mathrm{O}\right)_{20}{ }^{+}$.

The other reference ion chosen for comparison is tetramethylammonium $\left(\mathrm{TMA}^{+}\right)$. This ion interacts weakly with water, and although the structures of small water clusters can be affected by the ion charge, the perturbation by the ion to the intrinsic structures of water molecules at larger cluster sizes is minimal making this ion a good choice for essentially ion tagging a neutral water cluster. ${ }^{66} \mathrm{TMA}^{+}$(ionic radius $\sim 280 \mathrm{pm}$ (ref. 21)) is larger than $\mathrm{Gdm}^{+}$. However, this ion is expected to be at the surface of small clusters, and for much larger clusters in which the ion is likely to be at least partially solvated, the excluded volume effect on the overall hydrogen-bonding network of water molecules should be less. Because of the weak ion-water interactions, water molecules more optimally interact with other water molecules in the $\mathrm{TMA}^{+}$containing clusters. ${ }^{66}$

The IRPD spectrum of TMA $\left(\mathrm{H}_{2} \mathrm{O}\right)_{20}{ }^{+}$is compared to that of $\operatorname{Gdm}\left(\mathrm{H}_{2} \mathrm{O}\right)_{20}{ }^{+}$in Fig. 2c. The spectra are remarkably similar in the fOH region. The bonded $\mathrm{OH}$ region of $\operatorname{TMA}\left(\mathrm{H}_{2} \mathrm{O}\right)_{20}{ }^{+}$has a distinct, albeit poorly resolved peak at $\sim 3550 \mathrm{~cm}^{-1}$, but this peak is significantly less pronounced than the corresponding band in the spectrum of $\mathrm{Cs}\left(\mathrm{H}_{2} \mathrm{O}\right)_{20}{ }^{+}$. This suggests that there may be some clathrate-like structure to the water molecules in this cluster. ${ }^{67}$

\section{Free OH region $n=5-16$}

Information about the structure making or patterning effect of $\mathrm{Gdm}^{+}$on the arrangement of water molecules at the surface of the nanodrop can be inferred from differences in the $\mathrm{fOH}$ stretching regions (between 3630 and $3785 \mathrm{~cm}^{-1}$ ) of these ions (Fig. 3).

There are three well resolved and easily identifiable features in the spectrum of $\operatorname{Gdm}\left(\mathrm{H}_{2} \mathrm{O}\right)_{5}{ }^{+}$. The peak at $\sim 3740 \mathrm{~cm}^{-1}$ corresponds to the asymmetric stretch (a.s.) of a water molecule that only accepts a single hydrogen bond (acceptor-only, A) and

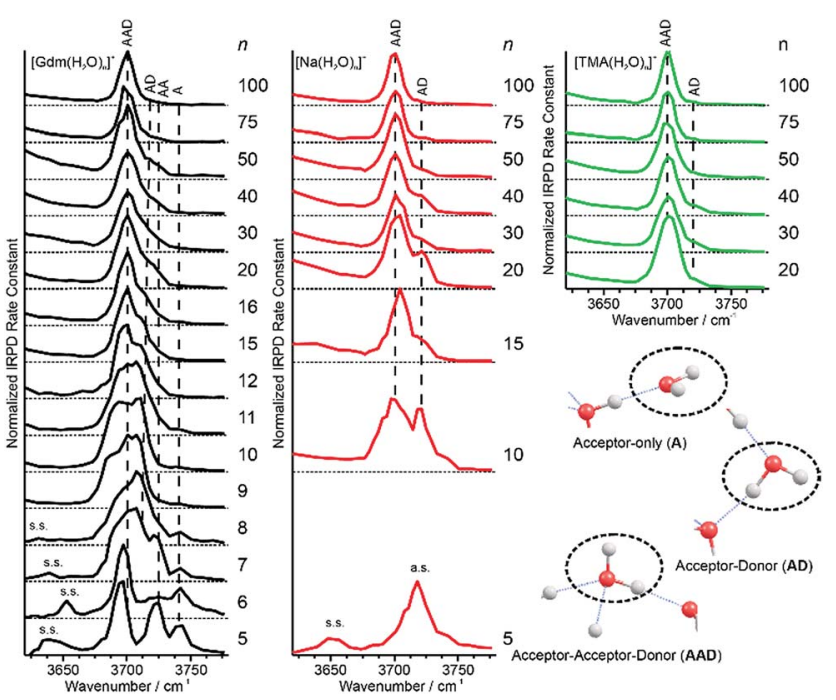

Fig. 3 Comparison of the free $\mathrm{OH}$ region of $\mathrm{Gdm}^{+}$(black), $\mathrm{Na}^{+}$(red) and $\mathrm{TMA}^{+}$(green) with $n$ between 5 and 100 obtained from IRPD measurements at $133 \mathrm{~K}$. Some of the observed vibrations in the free $\mathrm{OH}$ region, namely the acceptor-only $(\mathrm{A})$, acceptor-donor (AD) and acceptor-acceptor-donor (AAD) are highlighted in the lower right part of the figure. Oxygen atoms are red and hydrogen atoms are grey. 
the peaks at $\sim 3720$ and $\sim 3700 \mathrm{~cm}^{-1}$ originate from water molecules that accept two hydrogen bonds (acceptor-acceptor, AA) and accept two and donate one hydrogen bond (acceptoracceptor-donor, AAD). ${ }^{52,55-57,68}$ These features show that there are at least three different hydrogen-bonding motifs of water molecules in these small clusters. There is also a peak at $\sim 3640$ $\mathrm{cm}^{-1}$, which corresponds to the symmetric stretches (s.s.) of the A and AA water molecules. These same bands occur in the spectrum of $\mathrm{Gdm}\left(\mathrm{H}_{2} \mathrm{O}\right)_{6}{ }^{+}$but with different intensities, suggesting similarities in structures of these two clusters (see Fig. $\mathrm{S} 1 \dagger)$. For $\operatorname{Gdm}\left(\mathrm{H}_{2} \mathrm{O}\right)_{7}{ }^{+}$, the $\mathbf{A A D}$ band is considerably broader indicating the appearance of an additional band with a slightly higher frequency, which is attributed to a water molecule that accepts and donates a single hydrogen bond (acceptor-donor, AD). The $\mathbf{A}$ and AA bands diminish in intensity with increasing cluster size, and these bands are essentially absent in the spectra of clusters with $n \geq 9$. A band at $\sim 3580$ $\mathrm{cm}^{-1}$ appears in the spectrum of $\mathrm{Gdm}\left(\mathrm{H}_{2} \mathrm{O}\right)_{9}{ }^{+}$(Fig. 1), which indicates the presence of water molecules without free $\mathrm{OH}$ bands. For larger clusters, the fOH region consists of only broad overlapping $\mathbf{A D}$ and $\mathbf{A A D}$ bands and the relative intensity of the AAD stretch increases with cluster size. The AD stretch is no longer a distinct band but leads to a broadening of the AAD band towards higher energies for clusters with $n \geq 16$.

The fOH bands in the spectra of $\mathrm{Na}\left(\mathrm{H}_{2} \mathrm{O}\right)_{n}{ }^{+}, n=5,10$ and 15 differ significantly from those in the corresponding spectra of $\mathrm{Gdm}^{+}$(Fig. 3). The spectrum of $\mathrm{Na}\left(\mathrm{H}_{2} \mathrm{O}\right)_{5}{ }^{+}$has just a single symmetric stretch at $\sim 3650 \mathrm{~cm}^{-1}$ and the corresponding asymmetric stretch at $\sim 3740 \mathrm{~cm}^{-1}$, which is in good agreement with the previously reported spectrum..$^{53}$ For $\mathrm{Na}\left(\mathrm{H}_{2} \mathrm{O}\right)_{10}{ }^{+}$, there are two bands corresponding to $\mathbf{A D}$ and $\mathbf{A A D}$ water molecules, which are well resolved compared to these features in the spectrum of $\mathrm{Gdm}\left(\mathrm{H}_{2} \mathrm{O}\right)_{10}{ }^{+}$. This indicates that most of the AD and AAD oscillators in this sodium containing cluster experience a similar hydrogen bonding environment, whereas the environment is more heterogeneous for these oscillators in the corresponding $\mathrm{Gdm}^{+}$cluster. For clusters with 15 water molecules, the ratio of the $\mathbf{A A D}$ to $\mathbf{A D}$ band is significantly higher for $\mathrm{Na}^{+}$than for $\mathrm{Gdm}^{+}$, indicating that surface water molecules reside in a more ordered environment for the former ion.

\section{Structures of small $\mathrm{Gdm}^{+}$and $\mathrm{Na}^{+}$clusters}

In order to obtain qualitative information from the IRPD spectra, low-energy isomers at select cluster sizes were identified computationally and these structures are shown in Fig. 4.

Structures for these ions with five water molecules were reported previously, ${ }^{\mathbf{4 9 , 5 3}}$ but the low-energy structures for the larger clusters may not be global minimum structures owing to the complex conformational space and modest levels of theory used. It is almost certain that multiple isomers contribute to the IRPD spectra at the larger cluster sizes.

Consistent with results from experiment, the calculated structures indicate that the hydration of $\mathrm{Gdm}^{+}$and $\mathrm{Na}^{+}$differs significantly. For $\mathrm{Na}\left(\mathrm{H}_{2} \mathrm{O}\right)_{5}^{+}$, the first hydration shell is complete with four water molecules that are evenly dispersed around the central $\mathrm{Na}^{+}$, and the fifth water molecule occupies a

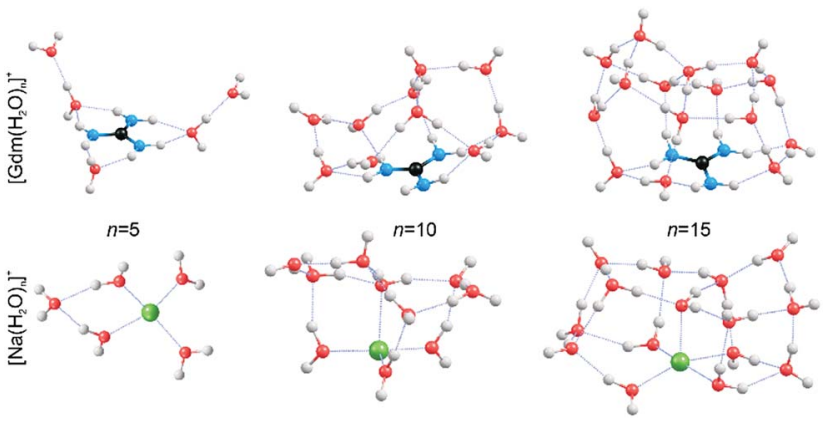

Fig. 4 Representative structures of $\left[\mathrm{Gdm}\left(\mathrm{H}_{2} \mathrm{O}\right)_{n}\right]^{+}$and $\left[\mathrm{Na}\left(\mathrm{H}_{2} \mathrm{O}\right)_{n}\right]^{+}$ obtained from B3LYP/6-31++G** calculations. Oxygen, hydrogen, carbon, nitrogen and sodium atoms are shown as red, white, black, blue and green spheres, respectively.

second shell in which it accepts hydrogen bonds from two inner shell water molecules. In contrast, the first solvent shell is complete with three water molecules for $\mathrm{Gdm}\left(\mathrm{H}_{2} \mathrm{O}\right)_{5}{ }^{+}$and these water molecules only interact with the $\mathrm{NH}_{2}$ groups. The two additional water molecules occupy a second solvation shell and accept one hydrogen bond from an inner shell water molecule. In contrast to the more spherical hydration of $\mathrm{Na}^{+}$, the hydration of $\mathrm{Gdm}^{+}$occurs roughly in the plane of the molecule. No water molecules attach to the central carbon atom despite its partial positive charge. ${ }^{36,49}$

Comparisons between experimental and computed spectra of candidate low-energy structures for clusters with $n=6-9$ were performed (Fig. S1-S5 $\dagger$ ). For $\operatorname{Gdm}\left(\mathrm{H}_{2} \mathrm{O}\right)_{6}{ }^{+}$, the structure corresponds to one in which the core structure established for the smaller clusters continues such that each of the three interstitial water molecules in the inner shell form a single hydrogen bond to an outer shell water molecule (Fig. S1†). With $n \geq 7$, the onset of water bridges between the three distinct hydration sites of the first shell consisting of AD water molecules occurs, which broadens the band at $3700 \mathrm{~cm}^{-1}$ (see Fig. S2-5†). This occurs until $n=9$ where the absence of an $\mathbf{A}$ or $\mathbf{A A}$ band indicates that all water molecules donate and accept at least one hydrogen bond.

The absence of the A and AA stretches in the IRPD spectra at $n \geq 9$ indicates a change in the inner shell hydration of $\mathrm{Gdm}^{+}$ occurs. The orientation of water molecules that coordinate to two adjacent $\mathrm{NH}_{2}$ groups results in a separation of the second shell water molecules from each other by at least $870 \mathrm{pm}(\mathrm{O}-\mathrm{O}$ distance), which prevents hydrogen bonding interactions between water molecules in the second solvation shell. In order for every water molecule to donate and accept at least one hydrogen bond, the water molecules in the first solvation shell must rearrange by accepting a hydrogen bond from just one $\mathrm{NH}_{2}$ group. This rearrangement of shell structure is consistent with the appearance of the band at $3580 \mathrm{~cm}^{-1}$ (Fig. 1) attributed to ADD water molecules. ${ }^{54,64}$

The structural rearrangement of the inner solvation shell that starts to occur for $n \geq 9$ inferred from the IRPD spectra is also found in the computed structures (Fig. 4 and $\mathrm{S} 4-\mathrm{S} 5 \dagger$ ). For $\operatorname{Gdm}\left(\mathrm{H}_{2} \mathrm{O}\right)_{10}{ }^{+}$, there are no water molecules that occupy the 
interstitial sites in which one water molecule accepts hydrogen bonds from two $\mathrm{NH}_{2}$ groups (Fig. 4). Instead, water molecules only accept a single $\mathrm{H}$-bond from $\mathrm{Gdm}^{+}$. This arrangement of water around the central ion is favourable for optimizing the number of water-water hydrogen bonds. The linear $\mathrm{NH}_{2} \cdots \mathrm{OH}_{2}$ coordination pattern continues for larger clusters (Fig. 4) where water molecules start to form a dome-like structure above the central carbon atom of $\mathrm{Gdm}^{+}$. The broad $\mathrm{OH}$ feature for these clusters is consistent with the anisotropic environment of the water molecules in the $\mathrm{Gdm}^{+}$clusters in this size range.

The hydration is significantly different for the small sodium clusters where the second shell water molecule in $\mathrm{Na}\left(\mathrm{H}_{2} \mathrm{O}\right)_{5}{ }^{+}$ accepts hydrogen bonds from two inner shell water molecules, and subsequent water molecules can readily form two or more hydrogen bonds to other water molecules resulting in quasispherical solvation. The number of different water molecules, estimated by their local hydrogen bond environments, is fewer in the intermediate size clusters of $\mathrm{Na}^{+}$compared to that for $\mathrm{Gdm}^{+}$. This is consistent with the better resolved $\mathbf{A D}$ peaks in the spectra of $\mathrm{Na}^{+}$for $n=10$ and 15 compared to that for $\mathrm{Gdm}^{+}$. The lack of water interactions with the central carbon of $\mathrm{Gdm}^{+}$ results in quasi-planar growth of the cluster for $n \leq 8$, whereas $\mathrm{Na}^{+}$clusters undergo quasi-spherical growth. This results in a different arrangement of water molecules at the surface and differences in the fOH region of the IRPD spectra of these two ions at small cluster size.

\section{Energetics of the first hydration shell rearrangement}

In order to gain insight into why the coordination number of $\mathrm{Gdm}^{+}$changes with cluster size, the binding energies of a water molecule to $\mathrm{Gdm}^{+}\left(\mathrm{H}_{2} \mathrm{O}\right)$ at different sites in $\mathrm{Gdm}\left(\mathrm{H}_{2} \mathrm{O}\right)_{2}{ }^{+}$were calculated. The binding energy of a water molecule that forms a single hydrogen bond to the inner shell water molecule is $69 \mathrm{~kJ}$ $\mathrm{mol}^{-1}$. If the water molecule occupies an interstitial site and accepts two hydrogen bonds, one from each adjacent $\mathrm{NH}_{2}$, the binding energy is $80 \mathrm{~kJ} \mathrm{~mol}^{-1}$. Thus, each $\mathrm{H}$-bond in this configuration is $40 \mathrm{~kJ} \mathrm{~mol}^{-1}$. If instead the water is in the plane of $\mathrm{Gdm}^{+}$with an $\mathrm{N}-\mathrm{H} \cdots \mathrm{O}$ angle of $180^{\circ}$ to a $\mathrm{NH}_{2}$ group forming only a single hydrogen bond (the $\mathrm{N}-\mathrm{H} \cdots \mathrm{O}$ bond lengths were optimized while the other coordinates were constant), then the binding energy is $65 \mathrm{~kJ} \mathrm{~mol}^{-1}$.

Thus, the most energetic configuration for water is to bind between two adjacent $\mathrm{NH}_{2}$ groups at small cluster size, but the sum of energies of two linear $\mathrm{H}$-bonds with two different water molecules is greater than that of the two non-optimal H-bonds of a single water molecule occupying the interstitial site. After these interstitial sites are occupied by the first three water molecules, additional outer shell water molecules will have only a single hydrogen bond. As more outer shell water molecules are added, there is a driving force to gain water-water hydrogen bonds by pulling the inner shell water molecules from the interstitial sites so that there is more overall hydrogen bonding.

\section{Evidence for spherical clusters at large size}

Extrapolation of cluster data to obtain bulk phase properties has been done to obtain absolute electrochemical potentials, ${ }^{69}$ formation enthalpies of metal clusters $^{70}$ and the electron hydration enthalpy. ${ }^{71}$ The surface-to-volume ratio of a sphere changes as $n^{-1 / 3}$. The IRPD measurements clearly distinguish water molecules at the cluster surface with a fOH stretch from water molecules that have both hydrogen atoms involved in hydrogen bonds that are located in the interior or at the surface. For small clusters, effects of transition dipole moments and binding energies of individual water molecules must be known in order to evaluate experimental intensities. For sufficiently large clusters where these values should not depend strongly on cluster size, the ratio of the integrated $\mathrm{fOH}$ and the integrated HB band should be roughly linear with $n^{-1 / 3}$ and extrapolate to zero at infinitely large cluster size.

A plot of the ratio of fOH to HB intensities $(I(\mathrm{fOH}) / I(\mathrm{HB}))$ as a function of $n^{-1 / 3}$ obtained by integrating the IRPD intensities from $3650-3800 \mathrm{~cm}^{-1}$ and $2900-3650 \mathrm{~cm}^{-1}$, respectively, for $\mathrm{Gdm}^{+}, \mathrm{Na}^{+}$and $\mathrm{TMA}^{+}$are shown in Fig. 5 .

The uncertainties are obtained from four measurements of $\operatorname{Gdm}\left(\mathrm{H}_{2} \mathrm{O}\right)_{100}{ }^{+}$(see Fig. S7 $\dagger$ ) and these same relative uncertainties were used for all other cluster sizes. For $\mathrm{Na}^{+}$, the $I(\mathrm{fOH}) /$ $I(\mathrm{HB})$ is highest for $n=5$ where the first HB band is observed, and decreases rapidly with cluster size until $n \sim 20$. From $n=20$ to 100 , these data are linear and extrapolate to zero at infinite cluster size. Similar results are observed for $\mathrm{TMA}^{+}$.

In contrast, the $I(\mathrm{fOH}) / I(\mathrm{HB})$ values for $\mathrm{Gdm}^{+}$are much lower than those for $\mathrm{Na}^{+}$at small cluster size. $\mathrm{Gdm}^{+}$differs from $\mathrm{Na}^{+}$ in that the inner shell water molecules hydrogen bond directly to the ion and these contribute to the bonded $\mathrm{OH}$ region of $\mathrm{Gdm}^{+}$at these smaller cluster sizes. A clear decrease in $I(\mathrm{fOH}) /$ $I(\mathrm{HB})$ is not observed for $\mathrm{Gdm}^{+}$until $n \sim 12$, consistent with anisotropic solvation of $\mathrm{Gdm}^{+}$at smaller cluster size.

The $I(\mathrm{fOH}) / I(\mathrm{HB})$ values for all three ions are indistinguishable within the accuracy of these measurements for $n \geq 20$.

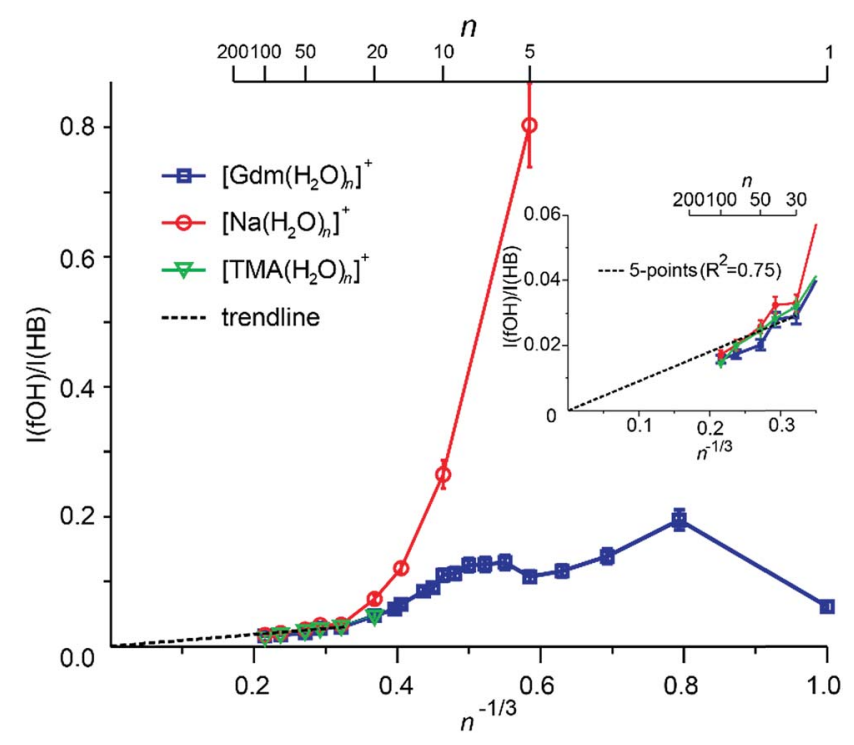

Fig. 5 The ratio for the integrated $\mathrm{fOH}$ to $\mathrm{HB}$ intensities $(/(\mathrm{fOH}) / /(\mathrm{HB}))$ obtained by numerical integration of the experimental IRPD intensities of $\mathrm{Gdm}^{+}$(blue), $\mathrm{Na}^{+}$(red) and $\mathrm{TMA}^{+}$(green) water drops as a function of $n^{-1 / 3}$. The inset shows an expansion for the clusters with $n=30-$ 100 and linear fit (black dashed line) to the five largest clusters. 
Results for a linear fit $\left(R^{2}=0.75\right)$ of these data for these larger clusters for all three ions is inset in Fig. 5. Both the linearity of these data and the $y$-intercept of zero indicate that the number of water molecules on the surface of the water nanodrops relative to those in the interior does not depend significantly on the identity of the cation for $n \geq 20$ and that these larger clusters are spherical to a large extent.

\section{Spectra of clusters with between 20 and 100 water molecules}

Although the $I(\mathrm{fOH}) / I(\mathrm{HB})$ values for the three ions are indistinguishable for $n \geq 20$, distinguishing spectral features persist for some of these larger clusters. The fOH region of the three ions are distinctly different at $n=20$, where the intensity of the AD band relative to the AAD band follows the order $\mathrm{Na}^{+}>\mathrm{Gdm}^{+}$ $>\mathrm{TMA}^{+}$. This indicates water molecules at the surface of the clusters are more optimally hydrogen bonded for $\mathrm{TMA}^{+}$than for $\mathrm{Na}^{+}$and $\mathrm{Gdm}^{+}$is intermediate. This general trend persists for $n$ $=30$ and 40 (Fig. 6f). The AD/AAD ratio becomes small and is indistinguishable for the three ions for $n$ between 50 and 100 . This indicates that the effect of the individual ions on the hydrogen bonding network of the water molecules at the surface of these clusters is negligible for $n \geq 50$.

There are also differences in the HB region for these different ions with $n \geq 20$, and the IRPD spectra of $\mathrm{Gdm}^{+}, \mathrm{Na}^{+}$and $\mathrm{TMA}^{+}$ for $n=30$ and 40 are shown in Fig. $6 \mathrm{a}$ and $\mathrm{b}$. The HB region for $\mathrm{Gdm}^{+}$and $\mathrm{TMA}^{+}$consists of a single broad band with a maximum around $3300-3400 \mathrm{~cm}^{-1}$. In contrast, this band for $\mathrm{Na}^{+}$is asymmetrical with lower intensity between 3100 and 3300 $\mathrm{cm}^{-1}$ at both cluster sizes consistent with bulk solution measurements. ${ }^{72}$ For $n=50,75$ and 100, the spectra of these ions are similar (Fig. 6c-e). The spectrum of $\mathrm{Na}\left(\mathrm{H}_{2} \mathrm{O}\right)_{50}{ }^{+}$has slightly higher intensity on the blue edge of the $\mathrm{HB}$ band compared to the other ions, but the intensity at the lower frequencies is nearly the same. The $\mathrm{HB}$ band for $\mathrm{TMA}^{+}$is much more similar to that of $\mathrm{Gdm}^{+}$than $\mathrm{Na}^{+}$and this difference is significant for clusters up to $n=50$. This is also supported by quantitatively comparing the $\mathrm{HB}$ band of $\mathrm{Gdm}^{+}, \mathrm{TMA}^{+}$and $\mathrm{Na}^{+}$ as presented in Table $\mathrm{S} 1 . \dagger$ These results show that the HB network of water molecules solvating $\mathrm{Gdm}^{+}$is structurally more similar to the $\mathrm{HB}$ network of $\mathrm{TMA}^{+}$hydrates than $\mathrm{Na}^{+}$hydrates. This indicates that $\mathrm{Na}^{+}$perturbs the $\mathrm{HB}$ network of water more than the other two ions, and that this perturbation of water structure propagates to the surface of nanodrops containing up to 50 water molecules.

In order to visualize possible effects of these ions on water structure, some representative low-energy structures were identified for these ions at $n=20$ and 40 (Fig. S8 $\dagger$ ). As was the case for $\mathrm{Gdm}\left(\mathrm{H}_{2} \mathrm{O}\right)_{10}{ }^{+}$, water molecules only accept single hydrogen bonds from the central ion and the central carbon atom does not interact with water resulting in a cavity above the plane of the ion. This is consistent with both experimental and theoretical results for $\mathrm{Gdm}^{+}$in water. ${ }^{36,44-46} \mathrm{TMA}^{+}$cannot form $\mathrm{H}$-bonds with water, which results in a similar exclusion zone as that above the plane of $\mathrm{Gdm}^{+}$. In contrast, $\mathrm{Na}^{+}$binds water strongly in the first solvation shell and this changes the optimal bond length to other water molecules (Fig. S8†).

\section{Comparison of $\mathrm{Gdm}^{+}$and $\mathrm{Na}^{+}$with 20 and 100 water molecules}

The IRPD spectra of $\mathrm{Gdm}^{+}$with 20 and 100 water molecules and the corresponding spectra for $\mathrm{Na}^{+}$are shown in Fig. 7a and $\mathrm{b}$. For $\mathrm{Gdm}^{+}$, the spectra differ most significantly in the relative intensities of the $\mathrm{fOH}$ and $\mathrm{HB}$ bands. For $n=100$, the relative contribution of the $\mathrm{fOH}$ is lower owing to the smaller surface-tovolume ratio for the larger cluster. The fOH peak is also narrower consistent with a significantly lower contribution of AD
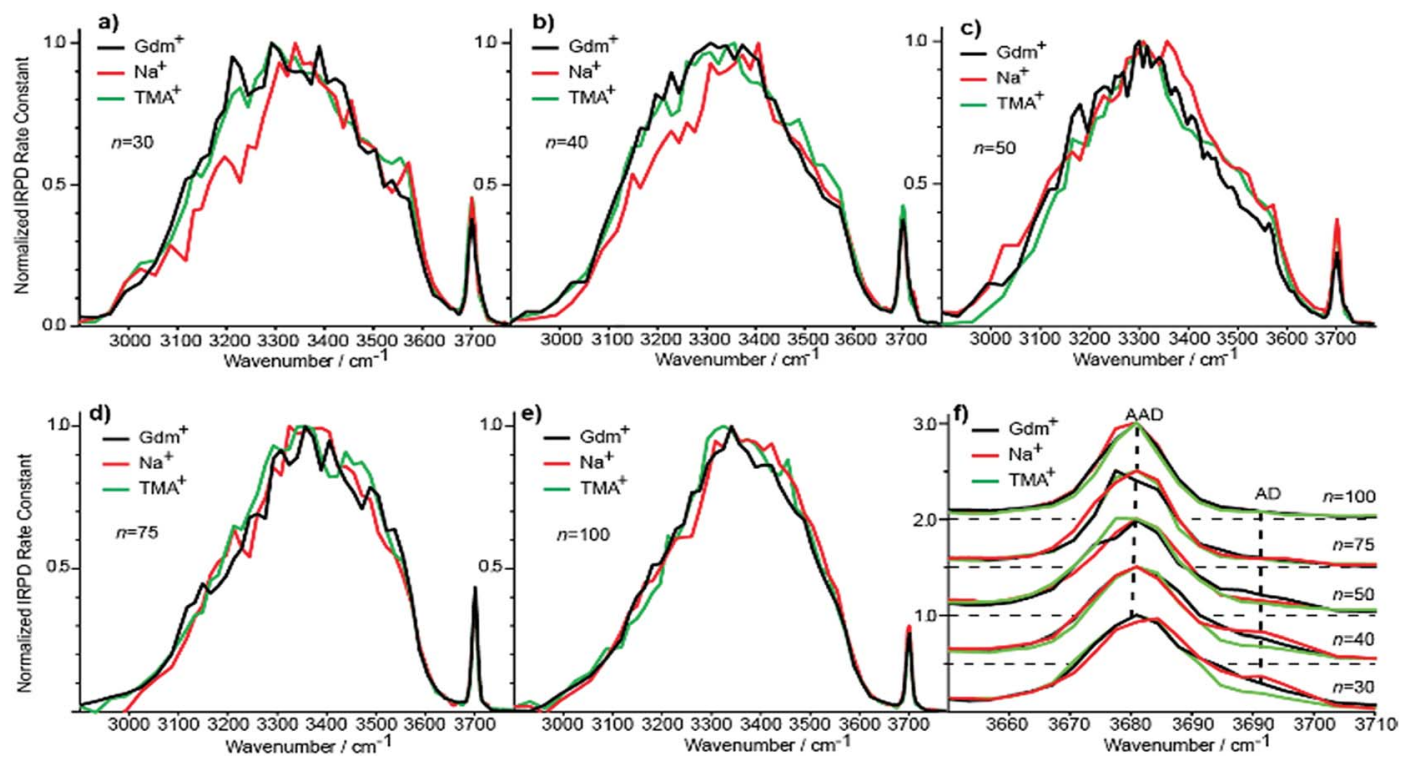

Fig. 6 Comparison of IRPD spectra between $2900-3800 \mathrm{~cm}^{-1}$ measured at $133 \mathrm{~K} \mathrm{for} \mathrm{Gdm}^{+}$(black), Na (red) and TMA (green) with (a) 30 , (b) 40, (c) 50, (d) 75 and (e) 100 water molecules. The $\mathrm{fOH}$ stretching region of all cluster sizes with the corresponding highlighted $A D$ and $A A D$ stretches is expanded in (f). 

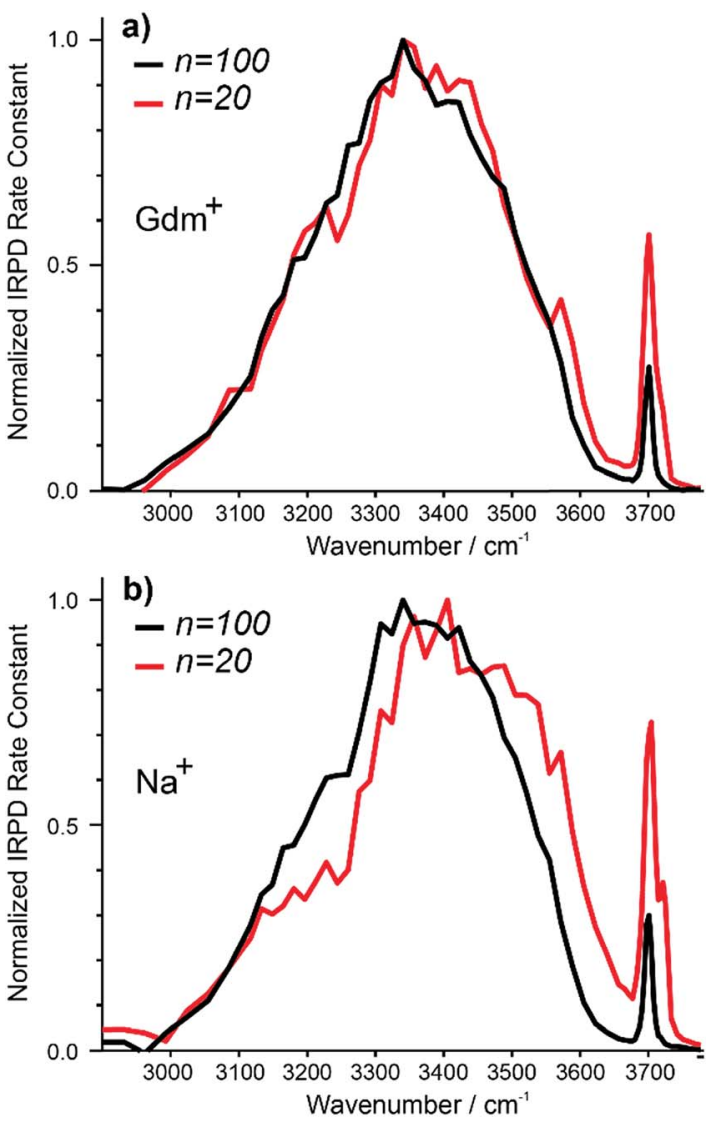

Fig. 7 Comparison of IRPD spectra between 2900-3800 cm $\mathrm{cm}^{-1}$ measured at $133 \mathrm{~K}$ for $\mathrm{Gdm}^{+}$(a) $\left[\mathrm{Gdm}\left(\mathrm{H}_{2} \mathrm{O}\right)_{100}\right]^{+}$(black), $\left[\mathrm{Gdm}\left(\mathrm{H}_{2} \mathrm{O}\right)_{20}\right]^{+}$(red) as well as (b) $\left[\mathrm{Na}\left(\mathrm{H}_{2} \mathrm{O}\right)_{100}\right]^{+}$(black), $\left[\mathrm{Na}\left(\mathrm{H}_{2} \mathrm{O}\right)_{20}\right]^{+}$ (red).

water molecules at the surface. This indicates that water at the surface of the larger cluster is more homogenous, whereas that in the smaller cluster is more disordered.

However, the intensity and appearance of the HB region is remarkably similar for these two cluster sizes indicating that the HB network between water molecules is similar.

In contrast, the differences in the spectra of $\mathrm{Na}^{+}$with 20 and 100 water molecules are more striking, both in the fOH and $\mathrm{HB}$ regions. More disorder at the surface of the smaller cluster is also indicated by the significant $\mathbf{A D}$ stretch, but the $\mathrm{HB}$ region for $\mathrm{Na}\left(\mathrm{H}_{2} \mathrm{O}\right)_{20}{ }^{+}$has more intensity around $3500-3600 \mathrm{~cm}^{-1}$ and less intensity between $3100-3300 \mathrm{~cm}^{-1}$ compared to that for $\mathrm{Na}$ $\left(\mathrm{H}_{2} \mathrm{O}\right)_{100}{ }^{+}$. These results indicate that the HB network of water molecules in the $\mathrm{Na}^{+}$clusters change significantly between $n=$ 20 and 100 , whereas there is only a minor change in the network of water molecules for $\mathrm{Gdm}^{+}$over this same size range.

\section{Conclusion}

The IRPD spectra of guanidinium hydrated with up to 100 water molecules along with spectra of corresponding hydrated ions of sodium and tetramethylammonium provide new insights into the unique way in which $\mathrm{Gdm}^{+}$interacts with water. For small clusters of $\mathrm{Gdm}^{+}(n<9)$, a detailed comparison of the IRPD spectra to spectra computed from low-energy structures indicates that $\mathrm{Gdm}^{+}$interacts strongly with water in the plane of the ion via $\mathrm{H}$-bonding in which three water molecules that form an inner shell each accept $\mathrm{H}$-bonds from adjacent $\mathrm{NH}_{2}$ groups and subsequent water molecules form a second solvation shell by hydrogen bonding to an inner shell water molecule. This nearplanar solvation continues until $n>8$ where more optimal water-water $\mathrm{H}$-bonding results in an expansion of the inner shell in which water molecules form only a singly linear $\mathrm{H}$-bond to the ion in order to optimize the number of water-water hydrogen bonds. Water forms a "dome" over the central carbon for even larger clusters despite the partial positive charge on the carbon atom as a result of little orbital density around this atom. ${ }^{49}$

The similar appearance of the $\mathrm{HB}$ region of $\mathrm{Gdm}^{+}$with 20 and 100 water molecules and the similar appearance of the $\mathrm{HB}$ region between similar size clusters of $\mathrm{Gdm}^{+}$and $\mathrm{TMA}^{+}$both indicate that $\mathrm{Gdm}^{+}$has a minimal effect on the hydrogen-bonding network of water molecules for these larger cluster sizes. Yet, $\mathrm{TMA}^{+}$and $\mathrm{Gdm}^{+}$are on opposite ends of the Hofmeister ion series and affect the stabilities of native proteins differently. The relatively weak interaction of both $\mathrm{Gdm}^{+}$and $\mathrm{TMA}^{+}$with water has led some to conclude that ion-water interactions do not play a significant role in the Hofmeister behaviour of ions. However, the way in which $\mathrm{Gdm}^{+}$interacts with water depends both on the cluster size and the orientation of water with respect to the ion. $\mathrm{Gdm}^{+}$effectively hydrogen bonds with water in the plane of the ion, but not above and below the plane where water-water hydrogen bonding is favoured. Enhanced water-water hydrogen bonds within the plane also results in a different orientation and $\mathrm{H}$-bonding motif of water to the ion when there are a sufficient number of water molecules. The way in which $\mathrm{Gdm}^{+}$interacts with water will thus depend on its local environment. $\mathrm{Gdm}^{+}$will interact with water in the plane of the ion even more strongly in an environment where water is excluded, such as the surface of a protein, and the hydrophobic nature of the ion above and below the plane should enhance such interactions with hydrophobic regions. Both the asymmetric hydration behaviour of $\mathrm{Gdm}^{+36,45,49}$ as well as its enhanced interactions with water in a limited solvated environment, may explain its effectiveness as a protein denaturant. These surfactant-like properties may stabilize hydrophobic regions of the protein in water and the enhanced interactions with water in a limited solvation environment should lower barriers to protein unfolding. This suggests that the mechanism by which $\mathrm{Gdm}^{+}$affects the stabilities of folded proteins is fundamentally different than that of many other ions, such as the sulfate dianion, where long-range effects of the ion on the hydrogen-bonding network of water molecules has been observed, both in gaseous clusters ${ }^{20}$ as well as to a more limited extent in the condensed phase. ${ }^{73} \mathrm{GdmCl}$ destabilizes protein structure, whereas $\mathrm{Gdm}_{2} \mathrm{SO}_{4}$ slightly stabilizes protein structure $;^{22,43}$ this opposite effect with these two anions may be related to their very different interactions with water and effects on the water-water hydrogen bonding network. Similar investigations into other ions in the Hofmeister series may lead to additional insights into these phenomena. 


\section{Acknowledgements}

The authors thank the National Science Foundation (grant CHE-1306720) for generous financial support of this research and are grateful to the German National Academy of Sciences Leopoldina (LPDS 2012-15) for a postdoctoral scholarship and financial support $(\mathrm{SH})$. The authors thank the University of California, Berkeley Molecular Graphics and Computation Facility (CHE-0840505).

\section{Notes and references}

1 A. M. Jubb, W. Hua and H. C. Allen, Annu. Rev. Phys. Chem., 2012, 63, 107-130.

2 P. B. Petersen and R. J. Saykally, Annu. Rev. Phys. Chem., 2006, 57, 333-364.

3 P. Jungwirth and B. Winter, Annu. Rev. Phys. Chem., 2008, 59, 343-366.

4 (a) H. J. Bakker, Chem. Rev., 2008, 108, 1456-1473; (b) Y. Marcus, Chem. Rev., 2009, 109, 1346-1370; (c) S. Enami and A. J. Colussi, J. Phys. Chem. B, 2013, 117, 6276-6281; (d) S. Enami, H. Mishra, M. R. Hoffmann and A. J. Colussi, J. Chem. Phys., 2012, 136, 154707; (e) S. Gopalakrishnan, D. Liu, H. C. Allen, M. Kuo and M. J. Shultz, Chem. Rev., 2006, 106, 1155-1175; (f) W. Hua, D. Verreault, Z. Huang, E. M. Adams and H. C. Allen, J. Phys. Chem. B, 2014, 118, 8433-8440.

5 J. Bockris and A. Reddy, Modern Electrochemistry 1-Ionics, Plenium Press, New York, NY, 1998.

6 A. V. Marenich, J. Ho, M. L. Coote, C. J. Cramer and D. G. Truhlar, Phys. Chem. Chem. Phys., 2014, 16, 1506815106.

7 P. Lo Nostro and B. W. Ninham, Chem. Rev., 2012, 112, 22862322.

8 Y. Zhang and P. S. Cremer, Curr. Opin. Chem. Biol., 2006, 10, 658-663.

9 F. Hofmeister, Arch. Exp. Pathol. Pharmakol., 1888, 24, 247260.

10 K. D. Collins, Methods, 2004, 34, 300-311.

11 K. D. Collins, Biophys. J., 1997, 72, 65-76.

12 H. Schott, J. Colloid Interface Sci., 1973, 43, 150-155.

13 T. Arakawa and S. N. Timasheff, Biochemistry, 1982, 21, 6545-6552.

14 G. I. Makhatadze, J. Phys. Chem. B, 1999, 103, 4781-4785.

15 G. I. Makhatadzea and P. L. Privalov, J. Mol. Biol., 1992, 226, 491-505.

16 P. E. Mason, C. E. Dempsey, G. W. Neilson, S. R. Kline and J. W. Brady, J. Am. Chem. Soc., 2009, 131, 16689-16696.

17 E. S. Courtenay, M. W. Capp and M. T. Record, Protein Sci., 2001, 10, 2485-2497.

18 J. N. Scott, N. V. Nucci and J. M. Vanderkooi, J. Phys. Chem. A, 2008, 112, 10939-10948.

19 J. T. O'Brien, J. S. Prell, M. F. Bush and E. R. Williams, J. Am. Chem. Soc., 2010, 132, 8248-8249.

20 J. T. O'Brien and E. R. Williams, J. Am. Chem. Soc., 2012, 134, 10228-10236.

21 Y. Marcus, J. Chem. Thermodyn., 2012, 48, 70-74.
22 T. Arakawa and S. N. Timasheff, Biochemistry, 1984, 23, 5924-5929.

23 S. Mayo and R. Baldwin, Science, 1993, 262, 873-876.

24 (a) K. K. Andersen, H. Wang and D. E. Otzen, Biochemistry, 2012, 51, 8371-8383; (b) E. A. Lipman, B. Schuler, O. Bakajin and W. A. Eaton, Science, 2003, 301, 1233-1235; (c) A. H. Crevenna, N. Naredi-Rainer, D. C. Lamb, R. Wedlich-Söldner and J. Dzubiella, Biophys. J., 2012, 102, 907-915.

25 P. H. von Hippel and K.-Y. Wong, Science, 1964, 145, 577580.

26 C. Dicko, J. M. Kenney, D. Knight and F. Vollrath, Biochemistry, 2004, 43, 14080-14087.

27 C. Camilloni, A. G. Rocco, I. Eberini, E. Gianazza, R. A. Broglia and G. Tiana, Biophys. J., 2008, 94, 4654-4661. 28 A. Kubíčková, T. Křrižek, P. Coufal, E. Wernersson, J. Heyda and P. Jungwirth, J. Phys. Chem. Lett., 2011, 2, 1387-1389.

29 E. P. O'Brien, R. I. Dima, B. Brooks and D. Thirumalai, J. Am. Chem. Soc., 2007, 129, 7346-7353.

30 X. Xu, P. Wu, W. Xu, Q. Shao, L. An, H. Zhang, C. Cai and B. Zhao, Phys. Chem. Chem. Phys., 2012, 14, 5824-5836.

31 J. Heyda, M. Kožíšek, L. Bednárova, G. Thompson, J. Konvalinka, J. Vondrášek and P. Jungwirth, J. Phys. Chem. B, 2011, 115, 8910-8924.

32 P. E. Mason, C. E. Dempsey, L. Vrbka, J. Heyda, J. W. Brady and P. Jungwirth, J. Phys. Chem. B, 2009, 113, 3227-3234.

33 P. E. Mason, J. W. Brady, G. W. Neilson and C. E. Dempsey, Biophys. J., 2007, 93, L04-L06.

34 M. Vazdar, F. Uhlig and P. Jungwirth, J. Phys. Chem. Lett., 2012, 3, 2021-2024.

35 (a) J. L. England, V. S. Pande and G. Haran, J. Am. Chem. Soc., 2008, 130, 11854-11855; (b) G. Graziano, Phys. Chem. Chem. Phys., 2011, 13, 12008-12014; (c) T. Koishi, K. Yasuoka, S. Y. Willow, S. Fujikawa and X. C. Zeng, J. Chem. Theory Comput., 2013, 9, 2540-2551; (d) M. Mandal and C. Mukhopadhyay, Phys. Rev. E: Stat., Nonlinear, Soft Matter Phys., 2013, 88, 052708; (e) A. G. Rocco, L. Mollica, P. Ricchiuto, A. M. Baptista, E. Gianazza and I. Eberini, Biophys. J., 2008, 94, 2241-2251; (f) K. H. Weiss Alexander, T. S. Hofer, B. R. Randolf and B. M. Rode, Phys. Chem. Chem. Phys., 2012, 14, 7012-7027; (g) D. Cui, S.-C. Ou and S. Patel, J. Phys. Chem. B, 2015, 119, 164-178.

36 P. E. Mason, G. W. Neilson, J. E. Enderby, M.-L. Saboungi, C. E. Dempsey, A. D. MacKerell and J. W. Brady, J. Am. Chem. Soc., 2004, 126, 11462-11470.

37 R. Godawat, S. N. Jamadagni and S. Garde, J. Phys. Chem. B, 2010, 114, 2246-2254.

38 W. K. Lim, J. Rösgen and S. W. Englander, Proc. Natl. Acad. Sci. U. S. A., 2009, 106, 2595-2600.

39 (a) C. E. Dempsey, T. J. Piggot and P. E. Mason, Biochemistry, 2005, 44, 775-781; (b) A. Huerta-Viga, S. R. Domingos, S. Amirjalayer and S. Woutersen, Phys. Chem. Chem. Phys, 2014, 16, 15784-15786.

40 A. Huerta-Viga and S. Woutersen, J. Phys. Chem. Lett., 2013, 4, 3397-3401. 
41 O. Shih, A. H. England, G. C. Dallinger, J. W. Smith, K. C. Duffey, R. C. Cohen, D. Prendergast and R. J. Saykally, J. Chem. Phys., 2013, 139, 035104.

42 I. L. Budyak, A. Zhuravleva and L. M. Gierasch, J. Mol. Biol., 2013, 425, 3522-3535.

43 C. E. Dempsey, P. E. Mason, J. W. Brady and G. W. Neilson, J. Am. Chem. Soc., 2007, 129, 15895-15902.

44 J. Hunger, S. Niedermayer, R. Buchner and G. Hefter, J. Phys. Chem. B, 2010, 114, 13617-13627.

45 P. E. Mason, G. W. Neilson, C. E. Dempsey, A. C. Barnes and J. M. Cruickshank, Proc. Natl. Acad. Sci. U. S. A., 2003, 100, 4557-4561.

46 J. Hunger, R. Neueder, R. Buchner and A. Apelblat, J. Phys. Chem. B, 2013, 117, 615-622.

47 S. T. van der Post, K.-J. Tielrooij, J. Hunger, E. H. G. Backus and H. J. Bakker, Faraday Discuss., 2013, 160, 171.

48 D. Y. Vorobyev, C.-H. Kuo, D. G. Kuroda, J. N. Scott, J. M. Vanderkooi and R. M. Hochstrasser, J. Phys. Chem. B, 2010, 114, 2944-2953.

49 R. J. Cooper, S. Heiles, M. J. DiTucci and E. R. Williams, J. Phys. Chem. A, 2014, 118, 5657-5666.

50 M. F. Bush, J. T. O'Brien, J. S. Prell, R. J. Saykally and E. R. Williams, J. Am. Chem. Soc., 2007, 129, 1612-1622.

51 Y. Shao, et al., Phys. Chem. Chem. Phys., 2006, 8, 3172-3191.

52 M. F. Bush, J. T. O'Brien, J. S. Prell, C.-C. Wu, R. J. Saykally and E. R. Williams, J. Am. Chem. Soc., 2009, 131, 1327013277.

53 D. J. Miller and J. M. Lisy, J. Am. Chem. Soc., 2008, 130, 15393-15404.

54 J. A. Fournier, C. J. Johnson, C. T. Wolke, G. H. Weddle, A. B. Wolk and M. A. Johnson, Science, 2014, 344, 1009-1012.

55 J.-W. Shin, N. I. Hammer, E. G. Diken, M. A. Johnson, R. S. Walters, T. D. Jaeger, M. A. Duncan, R. A. Christie and K. D. Jordan, Science, 2004, 304, 1137-1140.

56 D. J. Miller and J. M. Lisy, J. Am. Chem. Soc., 2008, 130, 15381-15392.

57 G. E. Douberly, A. M. Ricks and M. A. Duncan, J. Phys. Chem. A, 2009, 113, 8449-8453.
58 J. D. Rodriguez and J. M. Lisy, J. Am. Chem. Soc., 2011, 133, 11136-11146.

59 B. Bandyopadhyay, K. N. Reishus and M. A. Duncan, J. Phys. Chem. A, 2013, 117, 7794-7803.

60 R. S. Walters, E. D. Pillai and M. A. Duncan, J. Am. Chem. Soc., 2005, 127, 16599-16610.

61 J. S. Prell, J. T. O'Brien and E. R. Williams, J. Am. Chem. Soc., 2011, 133, 4810-4818.

62 (a) K. D. Collins, G. W. Neilson and J. E. Enderby, Biophys. Chem., 2007, 128, 95-104; (b) J. Mähler and I. Persson, Inorg. Chem., 2012, 51, 425-438.

63 D. R. Lide, CRC Handbook of Chemistry and Physics. A ReadyReference Book of Chemical and Physical Data, CRC, Taylor \& Francis, Boca Raton, Fla, London, 91st edn, 2010.

64 R. J. Cooper, T. M. Chang and E. R. Williams, J. Phys. Chem. A, 2013, 117, 6571-6579.

65 J. A. Fournier, et al., Proc. Natl. Acad. Sci. U. S. A., 2014, 111, 18132-18137.

66 J. S. Prell and E. R. Williams, J. Am. Chem. Soc., 2009, 131, 4110-4119.

67 T. M. Chang, R. J. Cooper and E. R. Williams, J. Am. Chem. Soc., 2013, 135, 14821-14830.

68 H.-C. Chang, C.-C. Wu and J.-L. Kuo, Int. Rev. Phys. Chem., 2005, 24, 553-578.

69 W. A. Donald, R. D. Leib, M. Demireva, J. T. O'Brien, J. S. Prell and E. R. Williams, J. Am. Chem. Soc., 2009, 131, 13328-13337.

70 T. Bachels, R. Schäfer and H.-J. Güntherodt, Phys. Rev. Lett., 2000, 84, 4890-4893.

71 (a) J. R. R. Verlet, A. E. Bragg, A. Kammrath, O. Cheshnovsky and D. M. Neumark, Science, 2005, 307, 93-96; (b) W. A. Donald, M. Demireva, R. D. Leib, M. J. Aiken and E. R. Williams, J. Am. Chem. Soc., 2010, 132, 4633-4640.

72 (a) P. A. Covert, K. C. Jena and D. K. Hore, J. Phys. Chem. Lett., 2014, 5, 143-148; (b) S. Nihonyanagi, S. Yamaguchi and T. Tahara, J. Am. Chem. Soc., 2014, 136, 6155-6158.

73 K. J. Tielrooij, N. Garcia-Araez, M. Bonn and H. J. Bakker, Science, 2010, 328, 1006-1009. 